\title{
Assessment of Risk Factors and Nutritional Status of Breast Cancer Patients Attending a Tertiary Care Hospital
}

\author{
Dr. Narasinga Rao Sadi ${ }^{1} \&$ Dr. Krishnaveni Avvaru ${ }^{2}$ \\ 1. Post Graduate student, ${ }^{2}$ Professor of Community Medicine, Andhra Medical College, Visakhapatnam.
}

\begin{abstract}
:
Background: Breast Cancer is the most common diagnosed malignancy in women worldwide and in India. The peak occurrence of breast cancer in developed countries is above the age of 50 years, where as in India it is above the age of 40 years. Factors like overweight and obesity, nulliparity, H/O abortions, family H/O breast cancer, H/O use of OCPs, non feeding of breast milk have been associated with breast cancer risk. Objectives: 1: To assess the risk factors of breast cancer 2:To assess the nutritional status of study population. Materials and methods: A hospital based cross sectional study was conducted among 50 histopathologically confirmed female breast cancer patients. A pretested questionnaire was administered and the study variables include age, age at menarche, menopausal status, history of abortions, family history of breast cancer, BMI etc. Results: The age of the study population ranged from 30-80yrs. Nearly 60\% of the study population were overweight and obese. Nulliparity and history of abortions were reported by $14 \%$ of study population and family history of breast cancer was seen among $8 \%$ of study participants .Regarding food intake in past one month, 50\% had less than usual intake; $6 \%$ had greater than usual and rest $44 \%$ stated that there was no change in the food intake.

Conclusion: Majority of the risk factors for breast cancer are modifiable, prevention of these risk factors will have significant impact on the occurrence of the breast cancer.
\end{abstract}

Key words: Breast cancer, risk factors, nulliparity, nutritional status, obesity.

\section{Introduction}

Breast Cancer is the most common diagnosed malignancy in women worldwide and in India. It ranks second to cervical cancer. The burden of breast cancer is increasing in both developed and developing countries. The peak occurrence of breast cancer in developed countries is above the age of 50 years, where as in India, it is above the age of 40 years ${ }^{1}$. India is facing a cancer epidemic and by 2020 the breast cancer is set to overtake cervical cancer as the most common type of cancer among all women in India ${ }^{2}$

Factors like overweight and obesity, nulliparity, $\mathrm{H} / \mathrm{O}$ abortions, family $\mathrm{H} / \mathrm{O}$ breast cancer, $\mathrm{H} / \mathrm{O}$ use of Oral contraceptive pills, non feeding of breast milk have been associated with breast cancer risk. Obesity leads to increased levels of fat tissue in the body that can store toxins and can serve as continuous source of carcinogens. Body fat is an important locus of endogenous oestrogen production and storage, and hence could increase the risk of breast cancer ${ }^{3}$.

Though a large number of women are affected with breast cancer, there is paucity of data on the nutritional status of breast cancer patients in India. Hence, an attempt was made to study the risk factors of breast cancer and to assess the nutritional status of breast cancer patients.

\section{Materials \& Methods}

The present study was a hospital based cross sectional study conducted during the months of November and December 2013. Fifty histopathologically confirmed breast cancer patients attending department of Oncology, King George Hospital, Visakhapatnam, were included and informed consent was taken prior to the study from all the study participants. A pretested questionnaire was administered and anthropometric measurements like weight and height were recorded . Body Mass Index was calculated using the standard formula. According to the South Asia specific regions ${ }^{4}$ the nutritional status was defined as follows.

1. $\quad<18.5 \mathrm{Kg} / \mathrm{M}^{2}-$ Chronic Energy deficiency

2. $\quad 18.5-22.9 \mathrm{~kg} / \mathrm{m}^{2}-$ Normal

3. $23-24.9 \mathrm{~kg} / \mathrm{m}^{2}$-over weight

4. $25-29.9 \mathrm{~kg} / \mathrm{m}^{2}$-Obese- I

5. $\geq 30 \mathrm{~kg} / \mathrm{m}^{2}$-Obese-II 


\section{Results}

A total of fifty breast cancer patients were included in the present study. Age of study population ranged from 30-80yrs. Majority were in the age group of 40-60yrs. Median age of study population was found to be $50 \mathrm{yrs}$ and mean age at occurrence of breast cancer among study population was 47.12 yrs. Regarding educational status, $66 \%$ were illiterate, $14 \%$ had primary education, $16 \%$ had secondary level of education and the rest were graduates. According to modified BG Prasad's classification ${ }^{5}$, more than half(54\%) of the study population belong to upper middle class followed by $36 \%$ in upper class and the rest $10 \%$ belong to lower class. Mean age at menarche was $13 y$ rs and more than half(54\%) attained menarche before the age of 13yrs.Nearly three fourths(74\%) attained menopause and $12 \%$ underwent hysterectomy before attaining menopause.

Table1: Distribution of risk factors among the study population:

\begin{tabular}{|l|l|}
\hline Risk factors & Frequency(N=50) \\
\hline Overweight \&Obesity & $58 \%(29)$ \\
\hline Nulliparity & $14 \%(7)$ \\
\hline History of abortions & $14 \%(7)$ \\
\hline Family history of breast cancer & $8 \%(4)$ \\
\hline Not given breast feeding & $8 \%(4)$ \\
\hline OCP usage & $2 \%(1)$ \\
\hline
\end{tabular}

Nearly $60 \%$ of the study population were overweight and obese. Nulliparity and history of abortions was reported by $14 \%$ of study population and family history of breast cancer was seen among $8 \%$ of study participants. All the study participants were consuming non-vegetarian diet.

Table 2: Clustering of Risk factors among the study population

\begin{tabular}{|l|l|}
\hline No of patients with risk factors & Frequency $(\mathrm{N}=50)$ \\
\hline Patients with single risk factor & $24 \%(12)$ \\
\hline Patients with two risk factors & $42 \%(21)$ \\
\hline Patients with three risk factors & $20 \%(10)$ \\
\hline Patients with four risk factors & $14 \%(7)$ \\
\hline
\end{tabular}
risk factors.

Regarding clustering of risk factors, $42 \%$ had a cluster of two risk factors and $20 \%$ had a cluster of three

Table 3: Distribution of study population based on BMI

\begin{tabular}{|l|l|}
\hline $\mathrm{BMI}\left(\mathrm{kg} / \mathrm{m}^{2}\right)$ & Frequency $(\mathrm{N}=50)$ \\
\hline$\leq 18.5 \mathrm{~kg} / \mathrm{m}^{2}$ (chronic energy deficiency) & $8 \%(4)$ \\
\hline $18.5-22.9 \mathrm{~kg} / \mathrm{m}^{2}$ (normal) & $34 \%(17)$ \\
\hline $23.0-24.9 \mathrm{~kg} / \mathrm{m}^{2}$ (over weight) & $22 \%(11)$ \\
\hline $25.0-29.9 \mathrm{~kg} / \mathrm{m}^{2}$ (obese I) & $26 \%(13)$ \\
\hline$\geq 30.0 \mathrm{~kg} / \mathrm{m}^{2}$ (obese $\left.\mathrm{II}\right)$ & $10 \%(5)$ \\
\hline
\end{tabular}

\section{Nutritional status:}

In our study only $34 \%$ had normal BMI and 58\% have BMI $>23$ i.e. obese(or) overweight. Dieitic history: When the question " Is there any loss of weight in the last six months " was asked 38\% reported that there was loss of weight. Regarding food intake in the past one month ,50\% had less than usual intake,6\% had greater than usual and rest $44 \%$ stated that there was no change in the food intake. Regarding eating problems, $18 \%$ had anorexia, $17 \%$ had complaints of nausea(or)vomiting and $3 \%$ stated that they feel full quickly .Nearly three fifths $(58 \%)$ reported that their physical activity was decreased in the past one month.

\section{Discussion}

The present study has given an insight into the risk factors for breast cancer. In our study majority were in age of 40-60yrs with median age of 50yrs. This finding is consistent with previous studies done by Kamath et $\mathrm{al}^{6}$ and Meshram et.al ${ }^{7}$. In our study, risk factors like nulliparity, history of abortions, family history of breast cancer were reported high, which were comparable to study by Kamath et.al and Bhadoria et.al ${ }^{8}$.

As overweight and obesity were positively associated with breast cancer, it was reported high in our study. Our findings are in concurrence with P.Singh et.al in their study on breast cancer observed that there is a strong association with overweight and obesity with breast cancer, where as Mukul dixit et.al in their study showed a negative association of overweight and obesity with breast cancer ${ }^{9}$. 


\section{Conclusions}

As majority of the risk factors for breast cancer are modifiable, prevention of these risk factors will have significant impact on the occurrence of the breast cancer.

\section{References}

[1]. Population based cancer registries consolidated report (1990-96). Available from: http://www.icmr.nic.in/ncrp/pbcr.pdf.[Last accessed on 2014 Jan31].

[2]. Priya shetty India faces growing breast cancer epidemic. The Lancet,2012;379(9820):992-993.

[3]. Singh P, Kapil U, Shukla NK, Deo S, Dwivedi SN. Association of overweight and obesity with breast cancer in India. Indian J Community Med 2011;36:259-62.

[4]. Malasian Association for the study of Obesity. Defining obesity -(http://www.maso.org.my/spom/chap3.pdf).

[5]. An updated prasad's socio economic classification for 2013.shankar reddy pudala, arlappa n, International journal of research and development of health. Ijrdh.com-ISSN:2321-1431. acessed on 13-11-2013.IJRDH2013;1(2):26-29.

[6]. Kamath R, Mahajan KS, Ashok L, Sanal TS.A study on risk factors of Breast Cancer among patients attending tertiary care hospital in Udipi district. Indian J Community Med 2013;38:95-9

[7]. Meshram II, Hiwarkar PA, Kulakarni PN. Reproductive risk factors for breast cancer: a case control study. Online J Health Allied Sci 2009;83:5.

[8]. Bhadoria A S, Kapil U, Sareen N, Singh P. Reproductive factors and breast cancer: A case-control study in tertiary care hospital of North India. Indian J Cancer 2013;50:316-21

[9]. Mukul dixit and Hemalatha mittal. Anthropometric factors and breast cancer risk among women in southern Rajasthan,India.IJCRR.2013;5(23);21-24 